\title{
An effective cytokine adjuvant vaccine induces autologous T-cell response against colon cancer in an animal model
}

\author{
Huanyu Ju ${ }^{1,2}$, Wenjing Xing ${ }^{1,2}$, Jinfeng Yang ${ }^{1,2}$, Yang Zheng ${ }^{1,2}$, Xiuzhi Jia ${ }^{1,2}$, Benning Zhang ${ }^{1,2}$ and Huan Ren ${ }^{1,2^{*}}$
}

\begin{abstract}
Background: Despite recent advances in early detection and improvements in chemotherapy for colon cancer, the patients still face poor prognosis of postoperative recurrence and metastasis, the median survival for patients with metastatic colorectal cancer is approximately 22-24 months. Some immunotherapeutic approaches had been attempted in colon cancer patients to significantly increase overall survival. A vaccine based approach has shown a novel direction for colon cancer prevention and therapy.

Methods: In this study, the experiments were designed including prevention and therapeutic stages in order to attain effect against tumor recurrence in clinical settings. The anti-tumor efficacy of a novel cytokine adjuvant vaccine that contained cytokines GM-CSF and IL-2 and inactivated colon CT26.WT whole cell antigen was evaluated in BALB/c mouse tumor models by measuring tumor growth post vaccination and the survival time of tumor-bearing mice, analyzing the expression and distribution of CD4, CD8, CD11C, CD80, CD86 and CD83 positive cells in control and treated mice by flow cytometry and immunochemistry. The tumor-specific cytotoxic T cells (CTL) were analyzed by tumor proliferation and the lactic dehydrogenates (LDH) release assays. IFN- $\gamma$, IL-2 and GM-CSF secretion in serum was assayed by ELISA.

Results: Our results suggested that cytokine adjuvant vaccine significantly inhibited tumor growth and extended the survival period at least 160d. It was found that the levels of CD8 $+T$ and the tumor-specific cytotoxicity were significantly higher in prevention and treatment group vaccinated by cytokine adjuvant vaccine. CD8 $+\mathrm{T}$ cells play a key role in anti-tumor response.

Conclusions: The novel GM-CSF and IL-2 based adjuvant vaccine effectively activated autologous T-cell response and represented a promising immunotherapeutic approach for patients with colon cancer.
\end{abstract}

Keywords: Colon cancer, CT26.WT, Cytokine adjuvant, Immunotherapy, Tumor vaccine

\section{Background}

Colon cancer is a common malignant tumor of the digestive tract [1]. It remains a challenge to treat advanced colon cancer due to postoperative recurrence and metastasis. Currently, surgical resection of primary colorectal lesions combined with adjuvant chemotherapy and radiation continues as the mainstay of therapy [2]. Unfortunately, around $30 \%$ of colorectal carcinoma patients are diagnosed with metastatic disease at initial presentation, and an additional 25-30 \% subsequently develops

\footnotetext{
* Correspondence: huanren2009@126.com; renhuan@ems.hrbmu.edu.cn 'Department of Immunology, Harbin Medical University, 157 Baojian Road, Harbin 150081, China

${ }^{2}$ Infection and Immunity, Key Laboratory of Heilongjiang Province, Harbin 150081, China
}

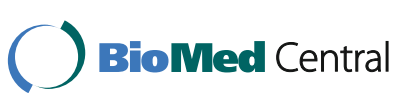

(c) 2016 The Author(s). Open Access This article is distributed under the terms of the Creative Commons Attribution 4.0 International License (http://creativecommons.org/licenses/by/4.0/), which permits unrestricted use, distribution, and reproduction in any medium, provided you give appropriate credit to the original author(s) and the source, provide a link to the Creative Commons license, and indicate if changes were made. The Creative Commons Public Domain Dedication waiver (http://creativecommons.org/publicdomain/zero/1.0/) applies to the data made available in this article, unless otherwise stated.

metastatic disease [3, 4]. Despite recent advances in early detection and improvements in chemotherapy, the median survival for patients with metastatic colorectal cancer is approximately $22-24$ months, with 5-year survival less than $5 \%$. Recently, additional immunotherapeutic approaches such as cytokine, cytokine-induced killers (CIK), mAb and tumor vaccine therapy in patients with advanced colon cancer significantly increase overall survival [5-8]. Moreover, these approaches also showed to be safe and effective. Amongst these, therapeutic tumor vaccines showed some promise. For example, preclinical studies demonstrated an enhanced antitumor activity of granulocyte-macrophage colony-stimulating factor (GM-CSF) or IL-2 producing murine colon tumor cell 
vaccines $[9,10]$ and each cytokine have been used as an adjuvant with cancer vaccines $[11,12]$. Nevertheless, so far the treatment with vaccines failed to significantly improve the 5-year survival of patients with colon cancer. Therefore, a new adjuvant therapeutic vaccine is needed.

GM-CSF is an important growth and differentiation factor for dendritic cells, which are potent antigenpresenting cells that can take up cellular proteins as tumor antigens [13]. For an effective antitumor response, preclinical studies suggested that GM-CSF secretion occur at the site of vaccination and high levels of the cytokine must be sustained for several days [14, 15]. GM-CSF-producing vaccines, together with autologous or allogeneic tumor cells, were frequently tested in preclinical and clinical studies [16-18], and antitumor responses were observed in various models such as clinical trials with pancreatic cancer patients [19-21]. Thus, a GM-CSF producing bystander cell line significantly improved the feasibility and efficacy of autologous or allogeneic tumor vaccines in human studies. IL-2 is a principle cytokine responsible for the differentiation of effector T cells. Relevant studies indicated that targeting IL-2 to tumor cells facilitated their elimination via enhanced $\mathrm{T}$ cell activation [9]. Therefore, IL-2 has the potential to aid in eliciting anti-tumor responses. Several studies suggested that IL-2 can be used in tumor vaccines, where it enhanced the antitumor response against several cancers [22, 23].

In the present study, we evaluated the efficacy of cytokine adjuvant (recombinant mouse GM-CSF and IL-2) vaccine pulsed with inactivated CT26.WT colon tumor cells via measuring the tumor-specific CTL activity and associated anti-tumor effect in a colon cancer model.

\section{Methods}

\section{Animals and cells}

Female and male BALB/c mice, 6 weeks old were purchased from the Beijing Experiment Animal Center, Chinese Academy of Sciences (Beijing, China). 130 mice were used for preliminary experiment, and 240 mice were used for formal experiment. All mice were kept under pathogen-free conditions in the animal center of the Harbin Medical University (Harbin, China). CT26.WT, a mouse colon adenocarcinoma cell line was purchased from the Shanghai Cell Biology Institutes, Chinese Academy of Sciences (Shanghai, China) and was cultured in RPMI medium 1640 (Hyclone, China) containing $10 \%$ heat-inactivated fetal calf serum (FCS), $2 \mathrm{mmol} / \mathrm{L}$ glutamine, penicillin $\mathrm{G}$ $(100 \mathrm{U} / \mathrm{mL})$, and streptomycin $(100 \mu \mathrm{g} / \mathrm{mL})$ at $37{ }^{\circ} \mathrm{C}$ in a humidified incubator supplemented with $5 \% \mathrm{CO}_{2}$.

Tumor model and vaccine production and immunization To establish the tumor model, CT26.WT tumor cells $\left(5 \times 10^{5}\right.$ cells per mouse) were injected subcutaneously into the neck of BALB/c mice. Tumors were observed after 8 days of cells inoculation in control mice. The cytokine adjuvant vaccine consisted of the following components: (1) GM-CSF \& IL-2 cytokines (R \& D, USA) adjuvants prepared by heparin and HSA (human serum albumin) package $(4500 \mathrm{IU} / 30 \mu \mathrm{l})$ and (2) CT26.WT tumor cells that were inactivated by mitomycin C (MMC) (Fuji Plant, Japan) for $2 \mathrm{~h}$ and then mechanically digested and counted. Finally, each vaccine dose was constituted by mixing $30 \mu \mathrm{l}$ of each, GM-CSF and IL-2 as well as $40 \mu \mathrm{l}$ of inactivated CT26.WT tumor cells $\left(1 \times 10^{6}\right.$ cells $)$. The cytokine adjuvant vaccine was immunization subcutaneously into the underarm and foot-pad of BALB/c mice for different times.

\section{Lymphocytes isolation and FACS analysis}

Lymphocyte cells were isolated from lymph nodes by manual dissociation and were suspended in Hanks buffer (Sigma, China). T cells were further purified by CD3 microBeads (Miltenyi Biotech, Germany) and counted. Splenocytes were isolated and treated with ACK red blood cell lysis buffer (Invitrogen, China) following manual dissociation, and then the similar protocol was used for isolation of as described above. Finally, lymphocytes $\left(1 \times 10^{6}\right)$ were stained with FITC-conjugated mAbs against mouse CD4 or CD8 and PerCP-Cy ${ }^{\mathrm{rm}} 5.5$-conjugated against mouse CD3, all purchased from BD Pharmingen (BD, USA). Next, these stained cells were analyzed using a FACS Caliber flow cytometer (BD, USA) and the Cell Quest software package (BD, USA).

\section{Cytotoxic T lymphocyte activity assay and cytokines detection}

To confirm the tumor-specific activity of cytotoxic $\mathrm{T}$ lymphocytes (CTLs), T lymphocytes were extracted at different time points. $\mathrm{CD}^{+} \mathrm{T}$ cells were isolated using CD3 microBeads (Miltenyi Biotech, Germany). $\mathrm{CD}^{+} \mathrm{T}$ cells were obtained by flow cytometry using anti-CD4 antibody by negative selection. Purified $\mathrm{CD}^{+} \mathrm{T}$ cells from each group of mice were cultured in RPMI 1640 medium containing $10 \%$ FCS. Next, effector T cells were mixed and incubated with target CT26.WT cells in a 96-well plates $(E: T, 50: 1)$ optimization for $24 \mathrm{~h}$. Thereafter, the supernatant from each well was collected and the cytolytic activity was measured by a LDH cytotoxicity detection kit (Nanjing jiancheng, China). For measuring CTL activity, we used the MTT cell viability detection kit (Sigma, China). The target CT26.WT cells were added into 96 well plates over night, and effector $\mathrm{T}$ cells suspensions were added in $E: T$ ratio of 50:1 optimization. The serum samples of each group of mice were collected and stored at $-80{ }^{\circ} \mathrm{C}$. The cytokines, IFN- $\gamma$, IL- 2 and GM-CSF levels were detected by using mouse cytokine ELISA Kit (RayBio ${ }^{\oplus}$, USA). 
Immunohistochemical staining analysis

Lymph nodes and tumors from each group were collected, fixed, embedded in paraffin, and sections stained for CD4, CD8, CD11c, CD80, CD86 and CD83 markers (Bioss, China) using the immunohistochemical staining kit (Santa, USA). Briefly, the sections were incubated with specific antibodies using a 1:200 dilution and subsequent detection with EnVison detection system (DAKO). Staining scores were quantified using $\mathrm{IHS}(\mathrm{IHS}=\mathrm{A} \times \mathrm{B}$, A stands for positive cells percentage in five visions, B stands for staining intensity for positive cells) [24]. The $\mathrm{H} \& \mathrm{E}$ staining for tumor were referenced by histological and histochemical methods [25].

\section{Statistical analysis}

The differences between groups were evaluated using Statistical Package for Social Science 20 (SPSS20.0). Statistical analysis was performed using a Student's $t$ test and survival differences among different groups of mice were evaluated with a log-rank test of the Kaplan-Meier survival curves. The statistical tests were two tailed and $p$ values $<0.05$ were considered to be statistically significant.

\section{Results \\ Optimization of the mouse tumor model and experimental design}

The schematic vaccine preparation and subsequent functional mechanisms for the induction of autologous T-cell anti-tumor response in a mouse colon cancer model is depicted in Additional file 1: Figure S1. Before analyzing treatment efficacy of the cytokine adjuvant vaccine, extensive standardization of different parameters to develop an ideal tumor model was applied, including the assessment of tumor formation time and volumes (Fig. 1a), specific anti-tumor effect of the vaccine (Fig. 1b), comparisons of tumor sizes between male and female mice (Fig. 1c), and optimized doses of inactivated tumor whole cell antigen in the vaccine (Fig. 1d). The results revealed that, there was no significant effect on the use of adjuvant or inactivated antigen alone, inactivated antigen obtained from $1 \times 10^{6}$ tumor cells in the vaccine had the most significant effect on inhibition of tumor development in the female mice that subcutaneously injected with $5 \times 10^{5}$ tumor cells. The tumor mass was generally established within 7-10 d post injection of the tumor cells. Based on these optimization steps, we compared the preliminary results of cytokine adjuvant vaccines between GM-CSF group, IL-2 group and GMCSF + IL-2 group by observing the survival period. The results revealed that combined application extended the survival period and significantly inhibited the tumor growth compared to single group (Fig. 1e). Then we further examined treatment efficacy and mechanism of the cytokine adjuvant vaccination in a $\mathrm{BALB} / \mathrm{c}$ mice colon cancer model. We divided the experimental procedures into the preventive and therapeutic stages, which may further strengthen anti-tumor effect during the course of tumor recurrence in clinical settings (Fig. 1f).

\section{Cytokine adjuvant vaccine enhanced anti-tumor immunity in the prevention and therapeutic models}

Then, we set up the tumor model by subcutaneously injection of CT26.WT colon cancer cells $\left(5 \times 10^{5}\right)$ at day 0 . In order to determine if the vaccine had a preventive or therapeutic potential during tumor progression, firstly, we vaccinated the mice in the Prevention group twice, at $10 \mathrm{~d}(\mathrm{~d}-10)$ and $3 \mathrm{~d}(\mathrm{~d}-3)$ before tumor cell injection; secondly, in the Treatment group, respective twice vaccinations were given before and after tumor cell injection $(d-10, d-3, d+7, d+14)$. The data showed that, whereas the weight of mice was not affected by vaccine inoculation (data not shown), the tumor growth as analyzed by tumor volumes and weights, was significantly inhibited in both groups of the vaccinated mice as compared to that in the controls. While 14 out of 14 (100\%) mice in the control group developed heavy tumors, only 6 out of 14 mice $(42.8 \%)$ and 2 out of 14 mice $(14.3 \%)$ in respective Prevention and Treatment groups had significantly less heavy tumors (Fig. $2 a$ and b). As seen in Fig. 2c, Tumor group mice at $49 \mathrm{~d}$ post tumor cell injection had an average tumor volume and weight of 18.17 $\pm 3.94 \mathrm{~cm}^{3}$ and $10.48 \pm 2.65 \mathrm{~g}$ respectively, Prevention group mice that were vaccinated two times had an average tumor volume and weight of $9.58 \pm 0.36 \mathrm{~cm}^{3}$ and $5.97 \pm 0.34 \mathrm{~g}$ whereas the Treatment group mice that were vaccinated four times had an average tumor volume $3.48 \pm 0.43 \mathrm{~cm}^{3}$ and weight of $2.14 \pm 0.21 \mathrm{~g}(p<$ 0.01). Furthermore, in comparison to the control group, the tumor inhibition rate was respective $57.1 \%$ and $85.7 \%$ in the Prevention and Treatment group. In addition, the survival rate was also assessed in the Control, Prevention and Treatment groups that each contained 20 mice, until $160 \mathrm{~d}$ post tumor cell injection. The data showed that mice in the Treatment group had greatly prolonged survival as compared with the Control group and Prevention group (Fig. $2 \mathrm{~d}, p<0.001$ ). Taken together, these results indicated that vaccine was vaccinated four times including prevention and therapeutic stages were better than vaccinated two times. Then we discussed the mechanism between Tumor group and Treatment group for repeating experiment.

\section{Variation of CD4 + and CD8+ T cell populations in peripheral lymphoid organs}

To further reveal variations of CD4+ and CD8+ T cells in the vaccinated and control mice, we stained the isolated CD3 + T cells from the draining $\mathrm{LN}$ and SP with 


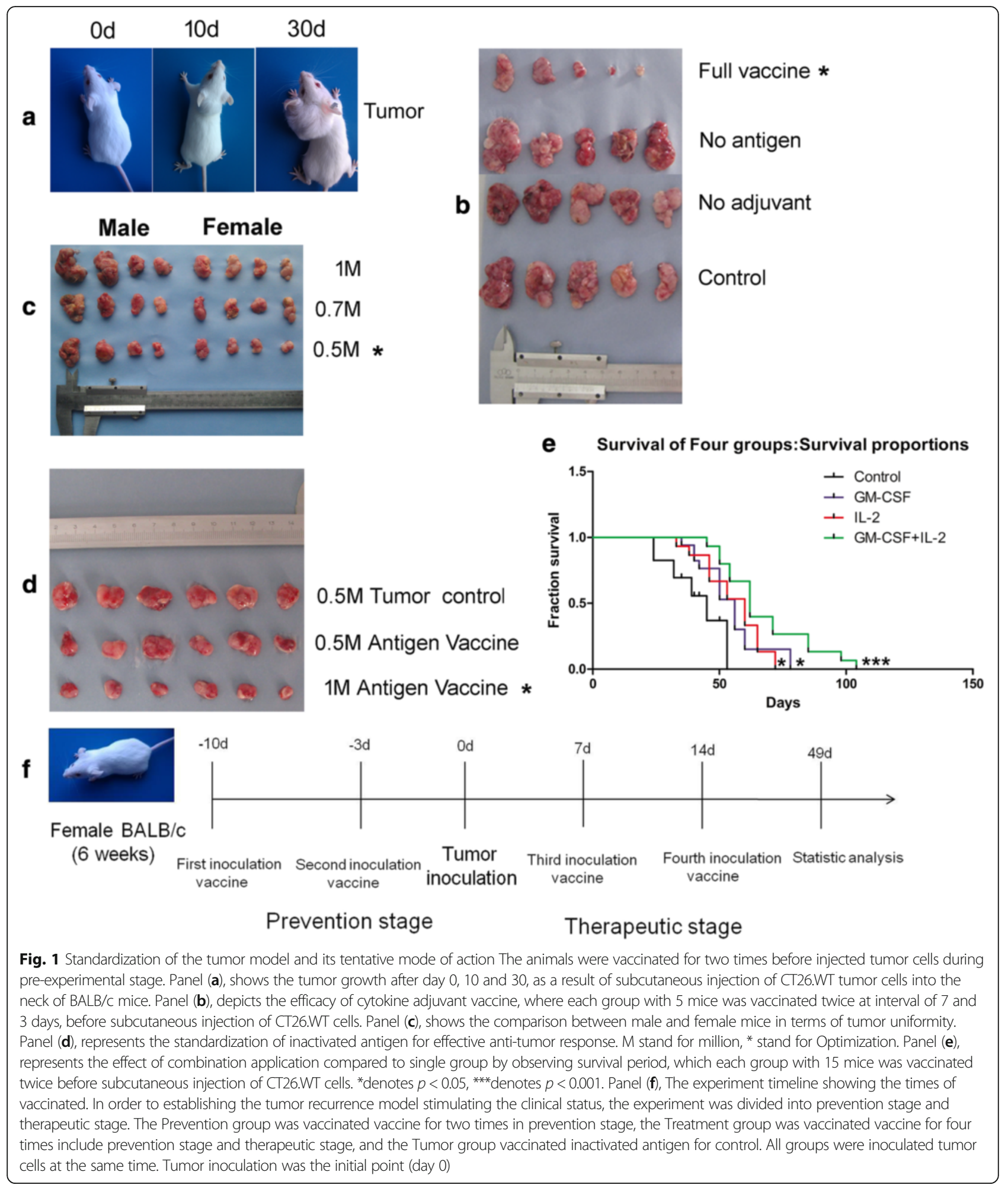

specific anti-CD4 and -CD8 antibodies and examined their expression by FACS. The statistical results showed that the fluctuation of $\mathrm{CD} 4 / \mathrm{CD} 8$ cell ratios during tumor progression after vaccination was significant and may reflect more rigorous and dynamic immune regulation and activity in the Treatment group (Fig. 3Aa and Bc). Moreover, ratios of $\mathrm{CD} 8 / \mathrm{CD} 3$ cells in Treatment group was higher than the Tumor group in all time points in LN and in time points $d-7$ to $d+13$ in SP (Fig. 3Ab and Bd). Then we found that the mice from the Treatment group were 


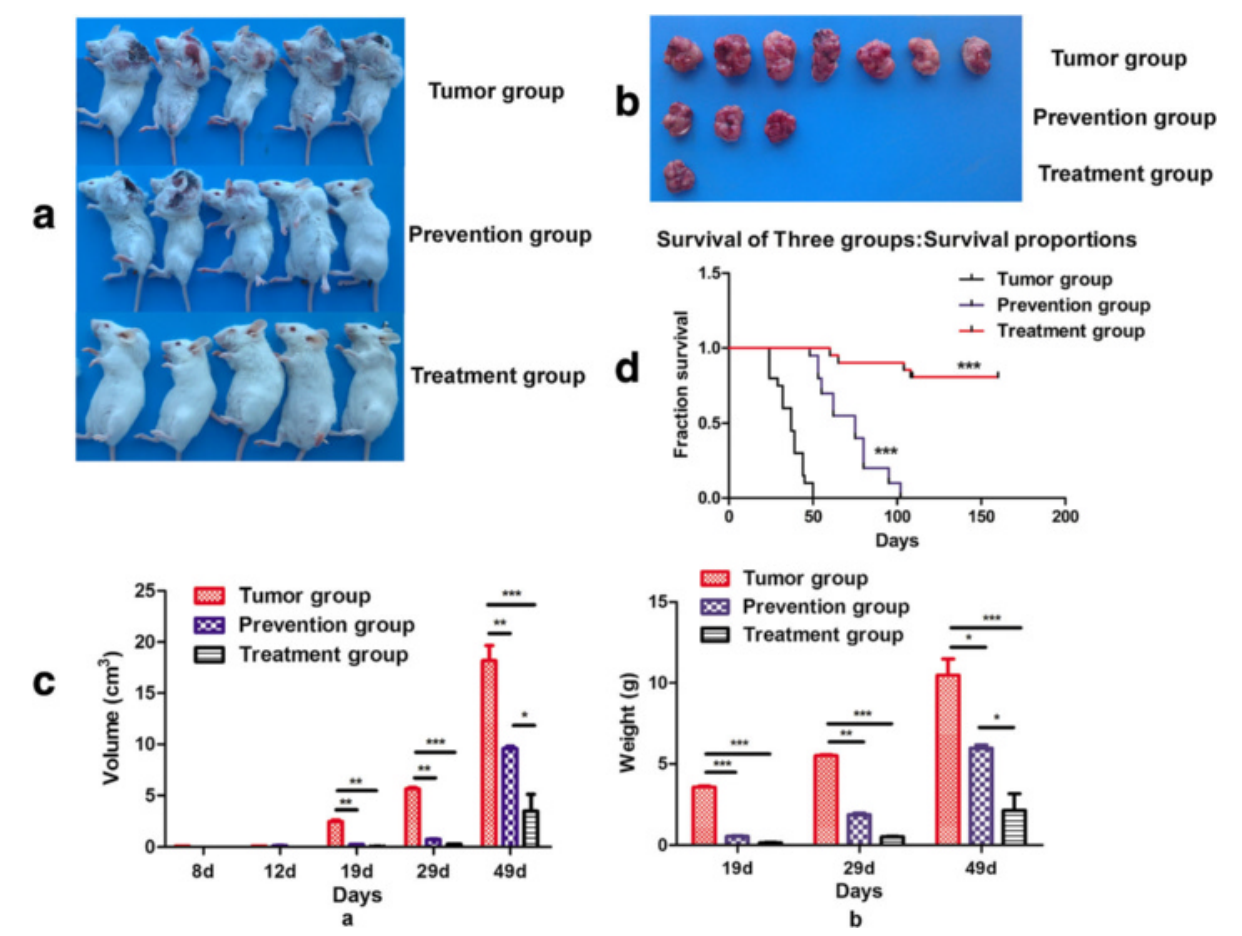

Fig. 2 Preliminary effect of the cytokine adjuvant vaccine Panel (a), shows the pictures of mice with tumors at day 49 from three different groups. Panel (b), shows the pictures of tumors excised from each group of mice and subsequently these tumors were used to calculate the tumor inhibition rate. Panel (c), represents the comparison of tumor volume (left) and weight (right) between tumor, prevention and treatment group. Panel (d), depicts a survival curve analyzed with a log-rank test of Kaplan-Meier curves using mice from Tumor (control), Prevention and Treatment group, where 20 mice of each group were followed for a period of $160 \mathrm{~d}$ (Kaplan Meier, $p<0.001$ ). ${ }^{* *}$ denotes $p<0.001$

not able to form tumors when they were re-inoculated with the tumor cells (data not shown). The results indicated that $\mathrm{T}$ cell immune memory formed after vaccination protecting against tumor attacks. Furthermore, we detected the ability of the tumor-specific $T$ cells.

\section{Vaccination enhanced the tumor-specific CTL responses}

We further analyzed whether such a cytokine adjuvant vaccination enhanced tumor-specific CTL response. $\mathrm{LDH}$ assay was performed to analyze the cytotoxic effect. The results demonstrated that $\mathrm{CD} 8+\mathrm{T}$ cells isolated from draining lymph nodes and the spleen of the vaccinated mice resulted in induction of higher $\mathrm{LDH}$ release by CT26.WT tumor cells in all time points in the Treatment group (Fig. 4a). In addition, the CTL activity was also examined by analyzing the target cell proliferation. The results showed that CT26.WT tumor cell proliferation was significantly reduced in samples that had CD8 + T cells from LN and SP of Treatment groups, at all time points as observed in Fig. 4b. These data suggested that $\mathrm{CD} 8+\mathrm{T}$ cells isolated from the vaccinated mice were more effective in generating CTL response. Next, we analyzed the levels of cytokines IFN- $\gamma$, IL-2 and GM-CSF most probably produced by activated $\mathrm{T}$ cells in serum. The data from different time points suggested that, the Treatment group had significantly periodic increases in the IFN- $\gamma$ and IL-2 levels as compared to the tumor group (Fig. 4c). Both cytokine levels peaked $2 \mathrm{~d}$ and $6 \mathrm{~d}$ post tumor cell inoculation and were significant higher in the vaccinated mice $(p<0.05)$. The levels of GM-CSF in serum in Treatment group were higher than the Tumor group which may stand for immune status for presenting antigen (Additional file 2: Figure S2). Collectively, this data suggested that the autolougous $\mathrm{T}$-cell response were effectively elicited and significantly stronger in the Treatment group.

\section{Analysis on distribution of CD4, CD8, CD11c, CD80, CD86 and CD83 cell populations in lymph nodes and tumor tissues}

We next analyzed distribution of CD4, CD8, CD11c, CD80, CD86 and CD83 cells in the lymph nodes by IHC in order to confirm the FACS results (Fig. 5A, and B). Consistently, we confirmed that, as compared to the Tumor group, the samples in Treatment group had greatly higher expression of CD4, CD8 and CD11c, suggesting a strong immune response that induced by the vaccination in the Treatment group (Additional file 3: Figure S3). It is interesting to note that the expression of CD8 and CD11c in the Treatment group maintained 


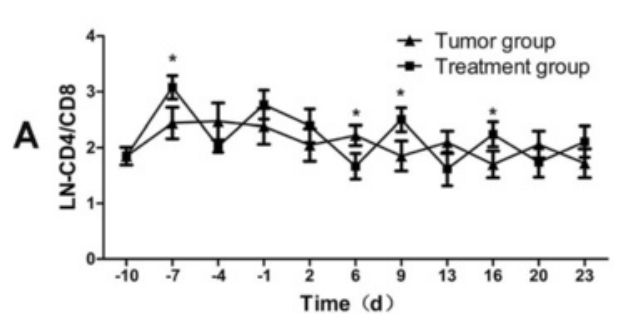

a

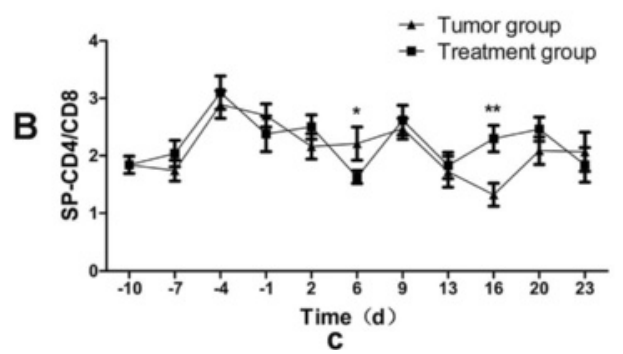

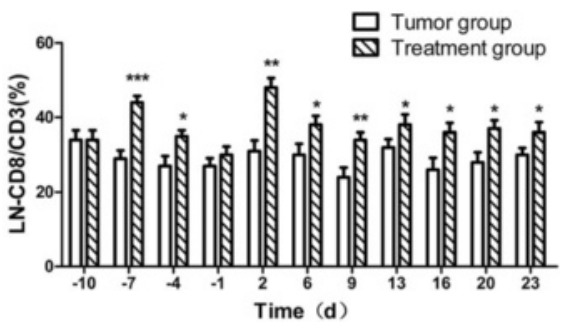

b

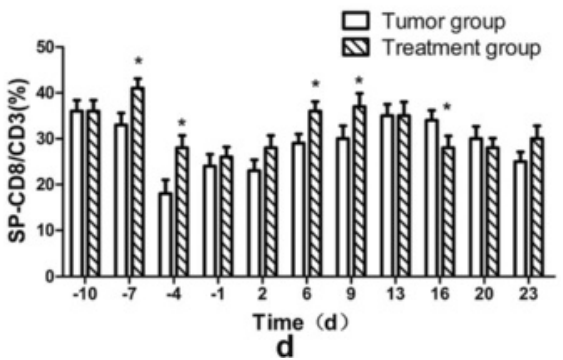

Fig. 3 Variation of CD4+, CD8+ cell populations in peripheral lymphoid organs Panel $\mathbf{A}$, depicts the CD4/CD8+ and CD8/CD3+ ratios as analyzed by flow cytometry analysis from the Lymph node, LN $(\mathbf{a}, \mathbf{b})$ Panel $\mathbf{B}$, depicts the CD4/CD8+ and CD8/CD3+ ratios as analyzed by flow cytometry analysis from the Spleen, SP (c, d), isolated from Tumor (control) and Treatment group mice at an interval of 3-4 d. *denotes $p<0.05$, * denotes $p<0.01,{ }^{* * *}$ denotes $p<0.001$

significantly higher than that in the control group during the tested period of time (Fig. 5A b and c). The level of CD11c expression may represent the relative amount of mature DC and effective antigen presentation (Fig. 5Ac). In order to further confirm our results, specific surface molecules of CD80, CD86 and CD83 on DC cells were detected. The results showed that the different variable for three molecules (Fig. 5B and Additional file 4: Figure S4). There is no significant difference except for a few time points for the levels of CD83 during the Tumor group and Treatment group (Additional file 4: Figure S4C). However, the levels of CD80 were higher than the levels of CD86 in lymph nodes. Furthermore, the expressions of CD80 and CD86 in Treatment group were significantly higher than Tumor group especially on the back of a few time points the same as the results of CD11c (Fig. 5B a and b). The results suggested that GM-CSF could induce activation and maturation of DC and maintain at relevantly high levels during the course. These data suggested that the vaccine may induce the body to produce a stronger $\mathrm{T}$ cell response due to higher number of mature DCs in the lymph nodes.

Moreover, we compared distribution of CD4+ T\& $\mathrm{CD} 8+\mathrm{T}$ cells in the tumor tissues in different groups. Firstly, HE staining revealed that, in comparison to the tumor group whose tumors were more concrete, tumor tissue samples had significantly wider spread of tissue damage in the Treatment group, in which we further observed greater infiltration of the lymphocytes into the tumor tissues. Noticeably, the CD8+ T cells in the Prevention and Treatment groups tended to accumulated in the damaged area (Fig. 5C). However, the number of CD4+ cells in the Tumor group was higher than the Treatment group and were located around the tumor cells. These cells may aid tumor growth by behaving as regulatory $\mathrm{T}$ cells with an immuno-suppressive function. Such a phenomenon warrants further investigations.

\section{Discussion}

In this study, we demonstrated safety and feasibility of a cytokine adjuvant vaccine in a mouse colorectal cancer model. To our best knowledge, this is the first study with a combination of the cytokines GM-CSF and IL-2 as a potent adjuvant of the vaccine that was applied in colon cancer models. Our data suggested that treatment with the cytokine adjuvant vaccine significantly delay or eradicate formation of colon cancer in this model. Thus, the vaccine and methodology may further used as cancer immunotherapeutic strategies to improve clinical recurrence after surgery.

It is shown that a sustained level of GM-CSF and IL-2 at the vaccination site is important for the activation of anti-tumor immune response [13], as GM-CSF acts to recruit DCs to present antigen, and IL-2 strengthens the T-cell response. Consistently, we showed that, if given sufficient amount in the colorectal cancer model, the vaccine may release GM-CSF and IL-2 in a good timing and effectively elicited an autologous $\mathrm{T}$ cells response, which achieved high efficacy in preventing from the tumor formation. Furthermore, there was a significant difference on the anti-tumor response in vivo between 


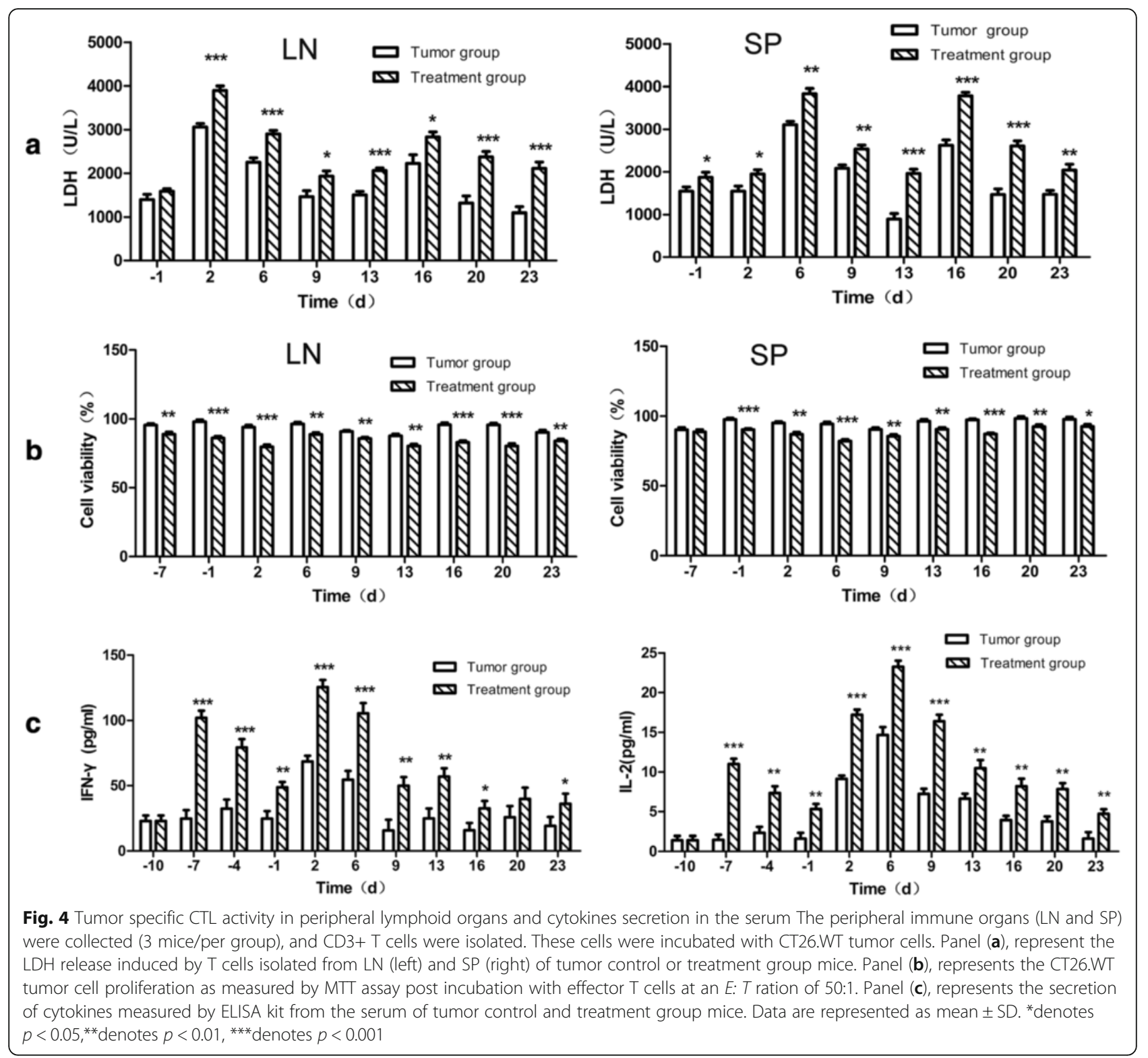

therapies in the prevention and treatment group, which adopted respective two and four times of the repeated vaccination. These indicate that the timing and times of vaccination procedures are important for an effective antitumor response. As approximately half of the colon cancer patients may suffer from tumor recurrence after surgery [26], our data imply that, combination of the inactivated resected tumor tissue as whole cell antigens and the cytokine adjuvant with optimized vaccination procedures on these patients may prevent from the tumor recurrence. Yet further investigations are highly warranted.

Besides significantly stronger CTL activity and prolonged survival rates in the treatment group, we observed greatly reduced ratios of weight/volume of the tumor mass in the treatment as compared to tumor group. The tumor mass in the treatment group mice were severely damaged and not as solid as that in the tumor group, in addition to our IHC analysis with an anti-CD8 antibody staining, we speculate that enhanced infiltration of the tumor specific $\mathrm{T}$ lymphocyte may contribute to such a phenomenon [27]. Furthermore, the levels of IFN- $\gamma$ in serum play an important role in increased anti-tumor immune responses [28]. We found higher levels of IFN- $\gamma$ in the serum of vaccinated mice. Moreover, IHC analysis of the lymph nodes showed higher levels of mature DC in the treatment group, which may provide specific antigen-MHC complexes for effective T cell response. Further IHC data with tumor tissues indicated that, the tumor group had a higher number of $\mathrm{CD} 4+\mathrm{T}$ cells, whilst the number of CD8 $+\mathrm{T}$ cells was higher in the treatment group. Such 


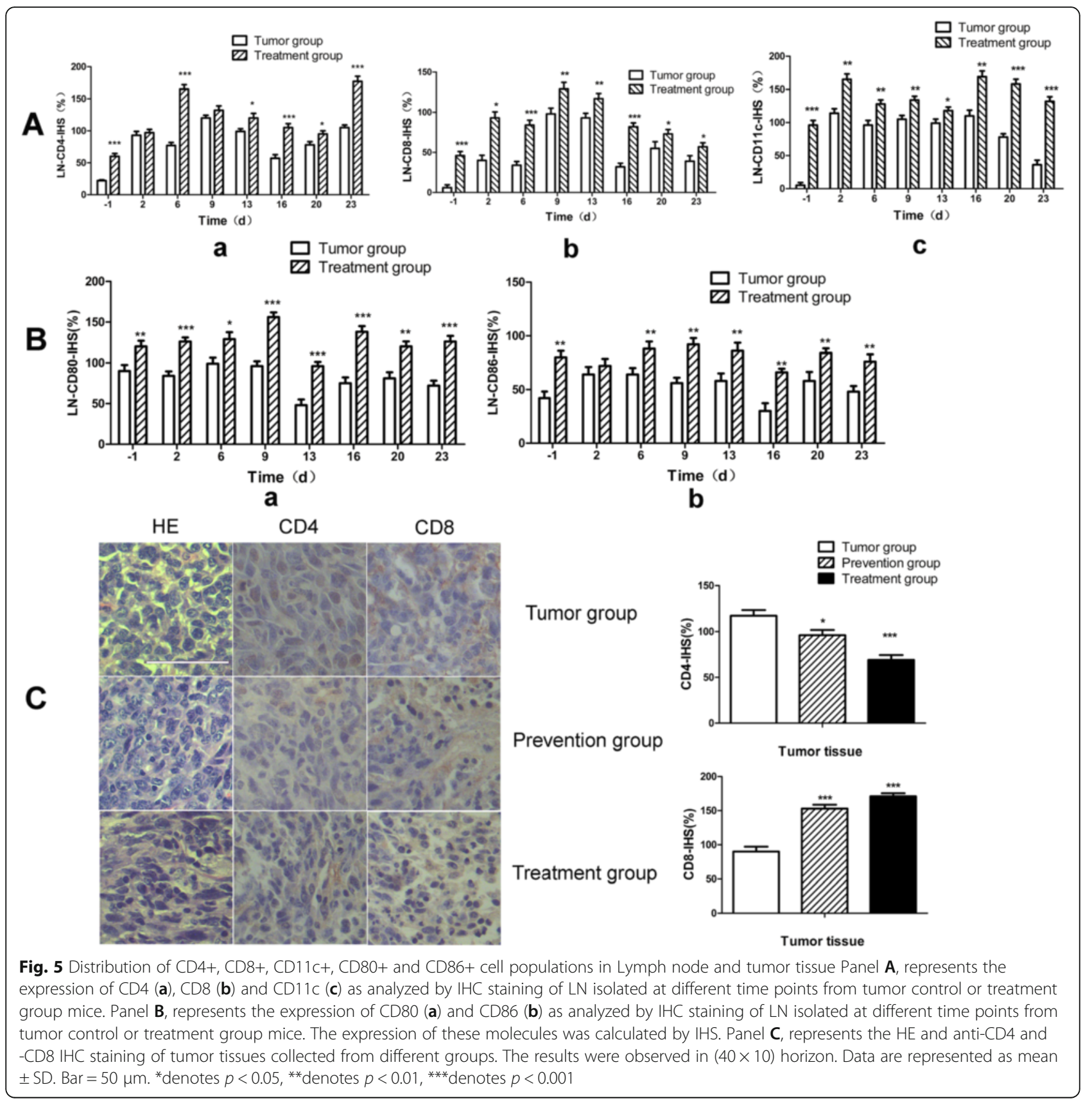

results may show that the effector $\mathrm{T}$ cells may display either anti-tumor or tumor-suppressive effect in different groups of animals [29]. Nonetheless, more specified mechanisms of the vaccine in vivo and its application to other types of tumor models are ongoing in our lab; if the data are confirmed, we will further test the effect in relevant clinical studies.

\section{Conclusion}

In summary, our data demonstrated that the cytokine (GM-CSF \& IL-2) adjuvant vaccine had a significant anti-tumor effect in colon cancer of a mouse model.
These results suggest that the effect maybe due to activating autologous $\mathrm{T}$-cell response and an evaluation of such a vaccine in other cancer models and colon cancer patients is warranted to further test its immunotherapeutic efficacy.

\section{Additional files}

Additional file 1: Figure S1. Provides schematic depiction of the vaccine formulation. (PDF $124 \mathrm{~kb}$ )

Additional file 2: Figure S2. Provides the levels of GM-CSF in serum. (PDF $209 \mathrm{~kb}$ ) 
Additional file 3: Figure S3. Provides the pictures for $\mathrm{IHC}$ staining for CD4, CD8 and CD11c in lymph nodes. (PDF 298 kb)

Additional file 4: Figure S4. Provides the pictures for $\mathrm{IHC}$ staining for CD80, CD86 and CD83 in lymph nodes. (PDF $445 \mathrm{~kb}$ )

\section{Abbreviations}

CTL: Cytotoxic T cells; FACS: Flow cytometry; GM-CSF: Granulocyte-macrophage colony-stimulating factor; HSA: Human serum albumin; IFN- $\gamma$ : Interferon gamma; IHC: Immunohistochemical; IL-2: Interleukin-2; LDH: The lactic dehydrogenates; LN: Lymph nodes; MMC: Mitomycin C; SP: Spleen

\section{Acknowledgments \\ Not applicable.}

\section{Funding}

The work was supported by the fund of University Nursing Program for Young Scholars with Creative Talents in Heilongjiang Province (UNPYSCT-2015027), the fund of National Natural Science Foundation of China (91229112), the fund of Education Department of Heilongjiang Province (12541438 and 12521180) and the fund of Health and Family Planning Commission of Heilongjiang Province (2013137).

\section{Availability of data and materials}

All data generated or analysed during this study are included in this published article and its Additional files.

\section{Authors' contributions}

We thank the study participants for this research. HR and BZ conceived the project, designed the experiments and supervised the experiments. HJ performed all experiments, analyzed the data and drafted the manuscript. $Y Z$ and JY helped with animal experiments. WX and XJ helped with samples detection. All authors read and approved the final manuscript no potential conflicts.

\section{Competing interests}

The authors declare that they have no competing interests.

\section{Consent for publication}

Not applicable.

\section{Ethics approval}

The study was approved by the Institutional Animal Care and Use Committee of Harbin Medical University (HMUIRB). All animal experiments were performed in compliance with the principles and procedures outlined in the Care and Use of Laboratory Animals guidelines, which is published by the China National Institute of Health.

\section{Received: 17 April 2016 Accepted: 20 September 2016} Published online: 26 September 2016

\section{References}

1. Haraldsdottir S, Einarsdottir HM, Smaradottir A, Gunnlaugsson A, Halfdanarson TR. [Colorectal cancer - review]. Laeknabladid. 2014;100(2):75-82.

2. Koido S, Ohkusa T, Homma S, Namiki Y, Takakura K, Saito K, Ito Z, Kobayashi $\mathrm{H}$, Kajihara M, Uchiyama K, et al. Immunotherapy for colorectal cancer World J Gastroenterol. 2013:19(46):8531-42.

3. Esin $\mathrm{E}$, Yalcin S. Maintenance strategy in metastatic colorectal cancer: A systematic review. Cancer Treat Rev. 2016;42:82-90.

4. Hasselgren K, Sandstrom P, Bjornsson B. Role of associating liver partition and portal vein ligation for staged hepatectomy in colorectal liver metastases: a review. World J Gastroenterol. 2015:21(15):4491-8.

5. Hughes T, Klairmont M, Broucek J, lodice G, Basu S, Kaufman HL. The prognostic significance of stable disease following high-dose interleukin-2 (IL-2) treatment in patients with metastatic melanoma and renal cell carcinoma. Cancer Immunol Immunother. 2015:64(4):459-65.

6. Hontscha C, Borck Y, Zhou H, Messmer D, Schmidt-Wolf IG. Clinical trials on CIK cells: first report of the international registry on CIK cells (IRCC). J Cancer Res Clin Oncol. 2011;137(2):305-10.
7. Jakel CE, Vogt A, Gonzalez-Carmona MA, Schmidt-Wolf IG. Clinical studies applying cytokine-induced killer cells for the treatment of gastrointestinal tumors. J Immunol Res. 2014;2014:897214

8. Hoyle M, Crathorne L, Peters J, Jones-Hughes T, Cooper C, Napier M, Tappenden P, Hyde C. The clinical effectiveness and cost-effectiveness of cetuximab (mono- or combination chemotherapy), bevacizumab (combination with non-oxaliplatin chemotherapy) and panitumumab (monotherapy) for the treatment of metastatic colorectal cancer after first-line chemotherapy (review of technology appraisal No.150 and part review of technology appraisal No. 118): a systematic review and economic model. Health Technol Assess. 2013:17(14):1-237.

9. Jain A, Slansky JE, Matey LC, Allen HE, Pardoll DM, Schulick RD. Synergistic effect of a granulocyte-macrophage colony-stimulating factor-transduced tumor vaccine and systemic interleukin-2 in the treatment of murine colorectal cancer hepatic metastases. Ann Surg Oncol. 2003;10(7):810-20.

10. Rosenberg SA. IL-2: the first effective immunotherapy for human cancer. J Immunol (Baltimore, Md: 1950). 2014:192(12):5451-8.

11. Nemunaitis J. Vaccines in cancer: GVAX, a GM-CSF gene vaccine. Expert Rev Vaccines. 2005:4(3):259-74

12. Greene JM, Schneble EJ, Jackson DO, Hale DF, Vreeland TJ, Flores M, Martin J, Herbert GS, Hardin MO, Yu X, et al. A phase I/lla clinical trial in stage IV melanoma of an autologous tumor-dendritic cell fusion (dendritoma) vaccine with low dose interleukin-2. Cancer Immunol Immunother. 2016:65(4):383-92.

13. Zheng L, Edil BH, Soares KC, El-Shami K, Uram JN, Judkins C, Zhang Z, Onners B, Laheru D, Pardoll D, et al. A safety and feasibility study of an allogeneic colon cancer cell vaccine administered with a granulocytemacrophage colony stimulating factor-producing bystander cell line in patients with metastatic colorectal cancer. Ann Surg Oncol. 2014;21(12): 3931-7.

14. Dranoff G, Jaffee E, Lazenby A, Golumbek P, Levitsky H, Brose K, Jackson V Hamada H, Pardoll D, Mulligan RC. Vaccination with irradiated tumor cells engineered to secrete murine granulocyte-macrophage colony-stimulating factor stimulates potent, specific, and long-lasting anti-tumor immunity. Proc Natl Acad Sci U S A. 1993;90(8):3539-43.

15. Borrello I, Sotomayor EM, Cooke S, Levitsky HI. A universal granulocytemacrophage colony-stimulating factor-producing bystander cell line for use in the formulation of autologous tumor cell-based vaccines. Hum Gene Ther. 1999:10(12):1983-91.

16. Leao IC, Ganesan P, Armstrong TD, Jaffee EM. Effective depletion of regulatory $T$ cells allows the recruitment of mesothelin-specific CD8 T cells to the antitumor immune response against a mesothelin-expressing mouse pancreatic adenocarcinoma. Clin Transl Sci. 2008;1(3):228-39.

17. Emens LA, Asquith JM, Leatherman JM, Kobrin BJ, Petrik S, Laiko M, Levi J, Daphtary MM, Biedrzycki B, Wolff AC, et al. Timed sequential treatment with cyclophosphamide, doxorubicin, and an allogeneic granulocytemacrophage colony-stimulating factor-secreting breast tumor vaccine: a chemotherapy dose-ranging factorial study of safety and immune activation. J Clin Oncol. 2009:27(35):5911-8.

18. Yamamoto Y, Hirakawa E, Mori S, Hamada Y, Kawaguchi N, Matsuura N. Cleavage of carcinoembryonic antigen induces metastatic potential in colorectal carcinoma. Biochem Biophys Res Commun. 2005;333(1):223-9.

19. Laheru D, Lutz E, Burke J, Biedrzycki B, Solt S, Onners B, Tartakovsky I, Nemunaitis J, Le D, Sugar E, et al. Allogeneic granulocyte macrophage colony-stimulating factor-secreting tumor immunotherapy alone or in sequence with cyclophosphamide for metastatic pancreatic cancer: a pilot study of safety, feasibility, and immune activation. Clin Cancer Res. 2008; 14(5):1455-63.

20. Lutz E, Yeo CJ, Lillemoe KD, Biedrzycki B, Kobrin B, Herman J, Sugar E, Piantadosi S, Cameron JL, Solt S, et al. A lethally irradiated allogeneic granulocyte-macrophage colony stimulating factor-secreting tumor vaccine for pancreatic adenocarcinoma. A phase II trial of safety, efficacy, and immune activation. Ann Surg. 2011;253(2):328-35.

21. Karan D, Van Veldhuizen P. Combination immunotherapy with prostate GVAX and ipilimumab: safety and toxicity. Immunotherapy. 2012;4(6):577-80.

22. Sivanandham M, Stavropoulos Cl, Kim EM, Mancke B, Wallack MK. Therapeutic effect of colon tumor cells expressing FLT-3 ligand plus systemic IL-2 in mice with syngeneic colon cancer. Cancer Immuno Immunother. 2002;51(2):63-71.

23. Ryan AE, Shanahan F, O'Connell J, Houston AM. Fas ligand promotes tumor immune evasion of colon cancer in vivo. Cell Cycle. 2006;5(3):246-9. 
24. Soslow RA, Dannenberg AJ, Rush D, Woerner BM, Khan KN, Masferrer J, Koki AT. COX-2 is expressed in human pulmonary, colonic, and mammary tumors. Cancer. 2000;89(12):2637-45.

25. Kmiec Z, Kiernan JA. Histological and Histochemical Methods: Theory and Practice. 5th edition, Scion Publishing, 2015, 571 pp. Folia Histochem Cytobiol. 2016;54(1):58-9.

26. Fatemi SR, Pourhoseingholi MA, Asadi F, Vahedi M, Pasha S, Alizadeh L, Zali MR. Recurrence and five -year survival in colorectal cancer patients after surgery. Iran J Cancer Prev. 2015;8(4):e3439.

27. Carretero R, Sektioglu IM, Garbi N, Salgado OC, Beckhove P, Hammerling GJ. Eosinophils orchestrate cancer rejection by normalizing tumor vessels and enhancing infiltration of CD8(+) T cells. Nat Immunol. 2015;16(6):609-17.

28. Tatsumi T, Huang J, Gooding WE, Gambotto A, Robbins PD, Vujanovic NL, Alber SM, Watkins SC, Okada H, Storkus WJ. Intratumoral delivery of dendritic cells engineered to secrete both interleukin (IL)-12 and IL-18 effectively treats local and distant disease in association with broadly reactive Tc1-type immunity. Cancer Res. 2003;63(19):6378-86.

29. Koumarianou A, Christodoulou MI, Patapis P, Papadopoulos I, Liakata E, Giagini A, Stavropoulou A, Poulakaki N, Tountas N, Xiros N, et al. The effect of metronomic versus standard chemotherapy on the regulatory to effector T-cell equilibrium in cancer patients. Exp Hematol Oncol. 2014;3(1):3.

\section{Submit your next manuscript to BioMed Central} and we will help you at every step:

- We accept pre-submission inquiries

- Our selector tool helps you to find the most relevant journal

- We provide round the clock customer support

- Convenient online submission

- Thorough peer review

- Inclusion in PubMed and all major indexing services

- Maximum visibility for your research

Submit your manuscript at www.biomedcentral.com/submit 